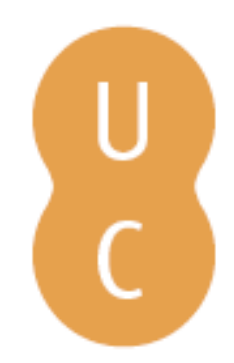

\title{
pompalina
}

\section{A etnomusicologia na Universidade Nova de Lisboa: os primeiros anos}

\author{
Autor(es): $\quad$ Castelo-Branco, Salwa El-Shawan
}

Publicado por: Imprensa da Universidade de Coimbra

URL

persistente: URI:http://hdl.handle.net/10316.2/30047

DOI: $\quad$ DOI:http://dx.doi.org/10.14195/978-989-26-0567-8_17

Accessed : $\quad$ 26-Apr-2023 11:46:42

A navegação consulta e descarregamento dos títulos inseridos nas Bibliotecas Digitais UC Digitalis, UC Pombalina e UC Impactum, pressupõem a aceitação plena e sem reservas dos Termos e Condições de Uso destas Bibliotecas Digitais, disponíveis em https://digitalis.uc.pt/pt-pt/termos.

Conforme exposto nos referidos Termos e Condições de Uso, o descarregamento de títulos de acesso restrito requer uma licença válida de autorização devendo o utilizador aceder ao(s) documento(s) a partir de um endereço de IP da instituição detentora da supramencionada licença.

Ao utilizador é apenas permitido o descarregamento para uso pessoal, pelo que o emprego do(s) título(s) descarregado(s) para outro fim, designadamente comercial, carece de autorização do respetivo autor ou editor da obra.

Na medida em que todas as obras da UC Digitalis se encontram protegidas pelo Código do Direito de Autor e Direitos Conexos e demais legislação aplicável, toda a cópia, parcial ou total, deste documento, nos casos em que é legalmente admitida, deverá conter ou fazer-se acompanhar por este aviso.

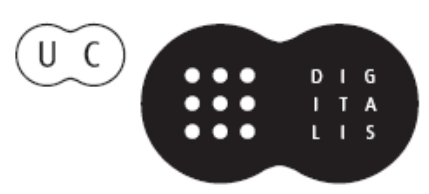




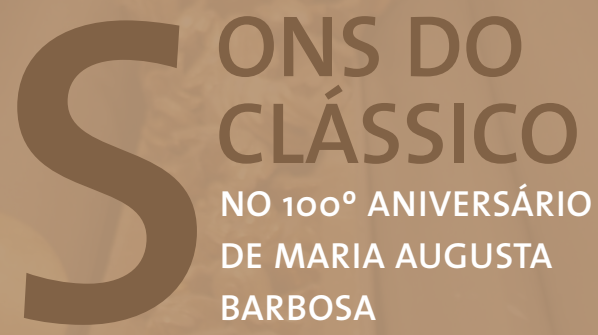

J. M. Pedrosa Cardoso

Margarida Lopes de Miranda COORDENAÇÃO 
Salwa El-Shawan Castelo-Branco

Universidade Nova de Lisboa

\section{A ETNOMUSICOLOGIA NA UNIVERSIDADE NOVA DE LISBOA: OS PRIMEIROS ANOS}

\section{Introdução}

A professora Maria Augusta Barbosa fundou o curso de Licenciatura em Ciências Musicais (LCM) na Faculdade de Ciências Sociais e Humanas (FCSH) da Universidade Nova de Lisboa, em 1980, institucionalizando o estudo científico da música no ensino universitário em Portugal. Embora tenha dirigido o Departamento de Ciências Musicais (DCM) que enquadra a LCM durante um período curto (1980-1983), deixou uma marca indelével no ensino da musicologia em Portugal, pela configuração do programa de Licenciatura, ancorada na sistematização do objecto da investigação musicológica proposta por Guido Adler em 1885 (Mugglestone 1981), que também enformou a investigação e o ensino da musicologia em diversas universidades na Europa e nos Estados Unidos de América ao longo do século xx, pela selecção criteriosa do corpo docente inicial, e pela seriedade, rigor e dedicação que imprimiu ao seu trabalho, inspirando todos que com ela colaboraram. A partir de 1983, após a aposentação da professora Maria Augusta Barbosa e ao longo de cinco anos, e novamente entre 1995 a 1997, tive o prazer e a honra de ser coordenadora do DCM, desenvolvendo o trabalho que ela havia iniciado.

Este texto em homenagem à Professora Maria Augusta Barbosa é um testemunho pessoal, ancorado na minha memória, naturalmente fragmentada e selectiva, dos primeiros anos da institucionalização da Etnomusicologia no âmbito da LCM na FCSH. Enquadra-se na abordagem etnomusicológica ao estudo do passado (Bohlman 2008, Shelemay 1980) e na perspectiva lançada 
pela Antropologia pós-moderna em meados da década de 80 (Clifford \& Marcus 1986) e adoptada pela Etnomusicologia na década seguinte que realça a importância da reflexividade, do dialogismo e da multi-vocalidade na escrita etnográfica, atribuindo ao etnógrafo os papeis de observador, intérprete, "escrivão" e "arquivista" das realidades que vivenciou e que constituem o seu objecto de estudo (Clifford 1986: 1-26).

\section{O primeiro encontro: verão de 1981}

O meu primeiro encontro com a professora Maria Augusta Barbosa teve lugar no início do verão de 1981. Na altura desempenhava o cargo de professora auxiliar de Etnomusicologia na New York University e de coordenadora do Mestrado em Etnomusicologia urbana que tinha lançado aquando da minha contratação naquela universidade, em 1979. Estava de visita a Portugal com meu marido, Gustavo Castelo-Branco, estando ambos a considerar a possibilidade de prosseguirmos as nossas carreiras académicas em Portugal.

A FCSH, fundada em 1977, funcionava nas instalações da antiga Direcção de Recrutamento Militar na Ave. de Berna, num conjunto de edifícios antigos de dois pisos adaptados para salas de aula e gabinetes. O DCM ocupava uma sala de aulas e um gabinete partilhado por todos os professores e pela professora Maria Augusta Barbosa no segundo andar de um dos edifícios.

O primeiro encontro com a professora foi marcante. As suas qualidades humanas e profissionais eram evidentes. No seu discurso enérgico, determinado e optimista, transparecia a complexidade da sua missão: estabelecer um novo domínio científico no meio académico Português, configurar um programa de Licenciatura de qualidade, assegurar um corpo docente competente e empenhado, ganhar apoios dentro e fora da universidade, atrair alunos qualificados para o novo curso. Outros desafios eram comuns a toda a FCSH, afectando também o DCM: melhorar, alargar e equipar as instalações, disponibilizar recursos bibliográficos e discográficos, assegurar a cobertura docente com professores qualificados.

Recebeu-me com grande cordialidade, manifestando interesse no meu percurso académico. Inteirou-me do currículo do DCM, dos seus objectivos e do elenco de professores que já o integrava, partilhando a sua preocupação 
com o facto de que na altura, mais de metade das cadeiras estavam sem cobertura docente por falta de professores qualificados. Na altura o corpo docente era constituído por personalidades destacadas no meio musical e cultural português, alguns dos quais foram docentes, ou continuaram a leccionar noutras instituições de ensino da música em Portugal ou no estrangeiro, nomeadamente os professores Gerhard Doderer (musicólogo e organista), João de Freitas Branco (musicólogo, critico e gestor cultural), Constança Capdeville (compositora, intérprete e pedagoga), João Ranita Nazaré (musicólogo e sociólogo) e a própria professora Maria Augusta Barbosa. ${ }^{132}$ Discutimos a oferta da Etnomusicologia, tendo a professora manifestado interesse em integrar, no programa da LCM, cadeiras em torno de culturas musicais extra-europeias e da abordagem teórica e metodológica da moderna Etnomusicologia. ${ }^{133}$

$A$ abertura de MAB às perspectivas da moderna Etnomusicologia que partilhei com ela logo no nosso primeiro encontro, a sua ambição para o DCM e a sua vontade de vencer o grande desafio a que se propunha deixaram-me entusiasmada com a perspectiva de contribuir para a institucionalização da disciplina em Portugal, um país com uma tradição de colecta de música de matriz rural por parte de etnógrafos e folcloristas, mas onde a moderna Etnomusicologia era até então desconhecida. ${ }^{134}$

\section{O ano lectivo de 1982-1983}

Volvido um ano, regressei a Portugal como "Professora Associada Convidada" a convite da FCSH, por iniciativa da professora Maria Augusta Barbosa,

132 Uma síntese do percurso biográfico, académico ou artístico assim como uma breve análise e listagem da obra literária ou musical de Maria Augusta Barbosa, João de Freitas Branco, Gerhard Doderer, Constança Capdeville e João Ranita Nazaré consta das entradas que lhes é dedicada em: Castelo-Branco, Salwa (ed.) (2010) Enciclopédia da Música em Portugal no Século xx. Lisboa: Círculo de Leitores/Temas de Debates.

133 Por moderna Etnomusicologia refiro-me ao desenvolvimento da disciplina a partir das décadas de 70 e 80 que se caracterizou pelo alargamento do seu objecto de estudo ao contexto urbano (Reyes-Schramm 1979), ao estudo dos média (Malm \& Wallis 1984) e das músicas populares (Manuel 2001) e à adopção generalizada de uma perspectiva antropológica, tendo o trabalho etnográfico como abordagem principal (Feld \& Fox 1994).

134 CF. Castelo-Branco (2010b) para uma análise do campo de saberes que se construiu em Portugal, desde meados do século xix até à década de 80 do século xx, em torno da recolha e do estudo da música em contextos rurais. 
acumulando funções docentes no Instituto Gregoriano que havia me dirigido um convite para leccionar Etnomusicologia e História da Música, iniciando o meu percurso académico mo país.

O interesse da professora Maria Augusta Barbosa pela revisão da oferta do DCM em Etnomusicologia era total. Com seu apoio e a aprovação do Conselho Científico da FCSH, a Etnomusicologia passou a integrar o programa de Licenciatura com duas cadeiras anuais obrigatórias. A primeira apresentava uma introdução ao percurso histórico e às tendências actuais da disciplina; a segunda centrava-se na teoria e método e na elaboração e execução de um projecto de trabalho de campo supervisionado pela docente. Esta oferta era inovadora quer nos EUA quer noutros países da Europa onde, regra geral, a Etnomusicologia era apenas oferecida aos níveis de Mestrado e Doutoramento. No meu próprio percurso académico, os conteúdos das duas cadeiras obrigatórias na LCM constavam do programa do primeiro ano do Mestrado quer na Columbia University onde completei o Doutoramento em Etnomusicologia em 1980, quer na New York University onde leccionei no programa de Mestrado em Etnomusicologia Urbana, entre 1979 e 1982. Nessa altura e mesmo na actualidade, na maioria das instituições, no âmbito da Licenciatura, a Etnomusicologia é introduzida através de uma cadeira de "Culturas Musicais do Mundo" centrada na audição e na análise de trechos musicais exemplificativos das características de algumas culturas musicais extra-europeias. ${ }^{135}$

Com efeito, a introdução tardia da Etnomusicologia em Portugal, a abertura e o apoio da professora Maria Augusta Barbosa, assim como a qualidade dos alunos das primeiras fornadas propiciaram o lançamento de um programa de ensino avançado a nível de Licenciatura. Esta oferta veio a dar frutos numa geração que, estimulada pela experiência de trabalho de campo na fase inicial da sua formação, escolheu a Etnomusicologia como área de especialização, continuando os seus estudos a nível de pós-graduação, ou aplicou

135 Desde a década de 80 que tem havido uma grande expansão em Universidades Europeias e Norte Americanas na oferta de uma cadeira de Licenciatura com as características acima descritas. Esta expansão é atestada pela proliferação de livros destinados ao apoio pedagógico de tais cadeiras, alguns já com várias edições, por exemplo: Titon (2009), Miller (2009), Nettl (2012), Wade (2009). Através destas cadeiras e dos livros que a elas se destinam, constituiu-se um canon de culturas musicais de conhecimento "obrigatório", entre as quais se destacam: África sub-sahariana, a Ilha de Java na Indonésia, sobretudo a prática e teoria associadas ao gamelão, e a tradição Hindustânica erudita do Norte da Índia. 
a abordagem etnomusicológica ao estudo da música erudita, ou a outras actividades profissionais.

Em sintonia com a professora Maria Augusta Barbosa, tracei como objectivos para o meu trabalho académico no DCM: "ministrar ensino actualizado em termos teóricos e metodológicos de modo a formar uma nova geração de etnomusicólogos competentes e internacionalmente competitivos; incentivar os jovens formandos a levar a cabo investigação etnomusicológica em Portugal e no espaço lusófono em torno de problemáticas actuais; encetar um dialogo científico com uma rede alargada de instituições e investigadores em Portugal e no estrangeiro de modo a colocar Portugal no circuito internacional de produção científica no domínio da Etnomusicologia” (Castelo-Branco 2010b).

As primeiras fornadas de alunos que tiraram as cadeiras de "Etnomusicologia I e II" acabaram com excelentes resultados. Vários apresentaram trabalhos que tinham desenvolvido no âmbito das duas disciplinas nos Encontros de Musicologia, organizados em colaboração com a Associação Portuguesa de Educação Musical (APEM), que vieram a ser publicados posteriormente no Boletim da mesma associação. O conjunto dos trabalhos foca problemáticas centrais na moderna Etnomusicologia: o papel social de um coro amador (Cardoso 1986), o Hot-Clube de Portugal enquanto instituição sócio-musical (Aresta e Gomes 1986), os espaços de performação do rock em Lisboa (Giga e Gaio 1986), a música na publicidade (Cymbron e Cruz 1986), a mudança musical num contexto rural (Carvalho e Oliveira 1987), as práticas musicais da comunidade judaica lisboeta (Borges e Miranda 1987), as transformações no repertório rural efectuadas por um grupo urbano de recriação (Correia e Neves 1987) e o papel do grupo folclórico federado (Sardo 1988). Três Licenciados das primeiras fornadas completaram os seus doutoramentos em Etnomusicologia. Actualmente colegas meus, ocupam cargos de docentes e investigadores no Ensino Superior em Portugal: João Soeiro de Carvalho e Maria de São José Côrte-Real na FCSH da UNL, e Susana Sardo na Universidade de Aveiro. Das gerações seguintes de Licenciados do DCM, vários prosseguiram com Doutoramentos em Etnomusicologia, sendo hoje profissionais de reconhecido mérito: Jorge Castro Ribeiro e Maria do Rosário Pestana são docentes na Universidade de Aveiro; Rui Cidra, António Tilly, Pedro Félix, Pedro Roxo e Leonor Losa são investigadores no Instituto de Etnomusicologia - Centro de 
Estudos em Música e Dança (INET-MD), unidade de investigação sediada na FCSH, tendo colaborado em vários projectos de investigação do INET-MD e na coordenação da Enciclopédia da Música em Portugal no Século xx, editada em quatro volumes, em 2010. ${ }^{136}$

\section{Considerações Finais}

Ao longo das últimas três décadas, o DCM consolidou a LCM, lançou cursos de Mestrado e Doutoramento em Ciências Musicais (com áreas de especialização em Musicologia Histórica, Etnomusicologia e Psicologia da Música), Artes Musicais, e Ensino da Música, institucionalizou e incrementou a investigação levada a cabo pelos seus docentes e discentes, e por outros investigadores portugueses e estrangeiros através de dois centros de investigação sediados na FCSH, o INET-MD - Instituto de Etnomusicologia - Centro de Estudos em Música e Dança, fundado por Salwa Castelo-Branco, em 1995, e o CESEM Centro de Estudos de Sociologia e Estética da Música, fundado por Mário Vieira de Carvalho, em 1997. Com efeito, trinta anos volvidos ao lançamento pela Professora Maria Augusta Barbosa da LCM, pioneira na Península Ibérica e no mundo lusófono, está patente o impacte do DCM no Ensino Superior da música e da musicologia, assim como no meio cultural Português em geral. Conforme demonstra João Soeiro de Carvalho num trabalho recente, o DCM graduou 407 Licenciados, 69 Mestres em Ciências Musicais, 25 Mestres em Artes Musicais, 64 Mestres em Formação de docentes e 17 Doutores em Ciências Musicais. Muitos dos diplomados do DCM desempenham cargos de relevância no Ensino Superior e em instituições culturais aos níveis nacional e regional. O DCM é hoje também reconhecido a nível internacional como uma instituição de excelência através do trabalho científico dos seus docentes e de alguns dos seus graduados, e da produção científica dos seus dois Centros de Investigação.

\footnotetext{
136 Pedro Félix e Rui Cidra são Licenciados em Antropologia, tendo tirado as cadeiras de Etnomusicologia por mim leccionadas no DCM. Rui Cidra defendeu o Doutoramento em Dezembro do ano passado. À excepção de Leonor Losa, mestre e doutoranda em Etnomusicologia, a defesa dos doutoramentos dos restantes investigadores acima referidos está programada para a primavera do corrente ano.
} 
Neste momento de grande transformação na sociedade portuguesa, na Europa e no mundo, importa fixar a memória do passado, elaborando uma história "multi-vocal" da institucionalização das Ciências Musicais no país, a partir do levantamento e análise da documentação disponível, assim como dos testemunhos de todos que nela colaboraram. ${ }^{137}$ Ao mesmo tempo, urge construirmos o futuro, respondendo às necessidades e aos desafios da sociedade actual e incrementando qualitativa e quantitativamente a nossa produção científica, norteados pelo mesmo espírito crítico e exigente que caracterizou a professora Maria Augusta Barbosa, prestando-lhe desse modo a nossa homenagem.

\section{Bibliografia Citada}

Aresta, Paula; Gomes, Bernardo de Azevedo (1986) "O Hot-Club de Portugal: uma instituição sócio-musical lisboeta”, in III Encontro Nacional de Musicologia. Actas, Boletim da Associação Portuguesa de Educação Musical 48: 51-52.

Bohlman, Philip (2008) "Returning to the Ethnomusicological Past," in Gregory Barz and James Cooley, Shadows in the Field: New Perspectives for Fieldwork in Ethnomusicology. 2 ed. Nova Iorque: Oxford University Press.

Borges, Maria José; Miranda, Zélia Maria (1987) "O culto religioso judaico: alguns aspectos da actual prática musical na comunidade lisboeta”, in IV Encontro Nacional de Musicologia. Actas, Boletim da Associação Portuguesa de Educação Musical 52: 26-28.

Cardoso, José Maria Pedrosa (1986) "Papel social de um coro amador na área de Lisboa", in III Encontro Nacional de Musicologia. Actas, Boletim da Associação Portuguesa de Educação Musical, 48: 47-50.

Carvalho, João Soeiro de; Oliveira, M. de S. José (1987) "Monsanto, uma tradição musical em mudança", in IV Encontro Nacional de Musicologia. Actas, Boletim da Associação Portuguesa de Educação Musical 52: 20-25.

Carvalho, João Soeiro (2012) "Três décadas de Ciências Musicais na Universidade Nova de Lisboa: balanço e novos desafios”. Trabalho inédito.

Castelo-Branco, Salwa (ed.) (2010) Enciclopédia da Música em Portugal no Século xx. Lisboa: Círculo de Leitores/Temas e Debates.

Castelo-Branco, Salwa (2010a) "Universidade Nova de Lisboa", in Enciclopédia da Música em Portugal no Século $x$, vol. IV. Lisboa: Círculo de Leitores/Temas e Debates.

\footnotetext{
137 Para um breve percurso histórico do DCM, cf. Castelo-Branco 2010a.
} 
Castelo-Branco, Salwa (2010b) "Etnomusicologia," in Enciclopédia da Música em Portugal no Século x, vol. II. Lisboa: Círculo de Leitores/Temas e Debates.

Clifford, James (1986) "Introduction: Partial Truths," in James Clifford \& Jorge Marcus (1986) Writing Culture: The Poetics and Politics of Ethnographic Writing. Berkley e Los Angeles: The Univeristy of California Press.

Clifford, James \& Marcus, Jorge (1986) Writing Culture: The Poetics and Politics of Ethnographic Writing. Berkeley e Los Angeles: The Univeristy of California Press.

Correia, Maria Clara; Neves, Rosa Clara (1987) "Sementes e a etnomusicologia em Portugal", in IV Encontro Nacional de Musicologia. Actas, Boletim da Associação Portuguesa de Educação Musical 52: 29.

Cymbron, Luísa; Cruz, Nuno Ivo (1986) "A importância da música na publicidade em Portugal", in III Encontro Nacional de Musicologia. Actas, Boletim da Associação Portuguesa de Educação Musical, 48: 55-57.

Feld, Steven \& Fox, Aaron (1994) "Music and Language", Annual Review of Anthropology 23: 25-53.

Giga, Idalete; Gaio, Ana Isabel (1986) "O fenómeno rock em Lisboa", in III Encontro Nacional de Musicologia. Actas, Boletim da Associação Portuguesa de Educação Musical, 48: 53-54.

Malm, Krister \& Wallis, Roger (1984) Big Sounds from Small Peoples. Londres: Constable.

Manuel, Peter (2001) "World Popular Music," 2a pt. in Stanley Sadie (ed.) The New Grove Dictionary of Music and Musicians. Londres: Macmillan.

Miller, Terry (2009) World Music: A Global Journey. 2 ed. Nova Iorque: Taylor and Francis.

Mugglestone, Erica (1981) "'Guido Adler's The Scope, Method and Aim of Musicology': A Translation with a Historico-Analtical Commentary," Yearbook for Traditional Music 13: 1-21.

Nettl, Bruno et. al. (2012). Excursions in World Music. 6 ed. Nova Iorque: Pearson.

Reyes, Schramm, Adelaide (1979) "Ethnic Music, the Urban Area and Ethnomusicology," Sociologus 1 - 19.

Shelemay, Kay (1980) "Historical Ethnomusicology: Reconstructing Falasha Liturgical History,” Ethnomusicology 24: 233-258.

Titon, Jeff (ed.) (2009) World of Music: An Introduction to the Music of the World People's. 3 ed. Nova Iorque: Schrimer.

Wade, Bonnie (2009) Thinking Musically: Experiencing Music, Expressing Culture. 2 ed. Nova Iorque: Oxford University Press. 